\title{
DIÁLOGOS ENTRE O RURAL E O URBANO - O PRIMITIVO COMO DISCURSOS DA CIVILIZAÇÃO
}

\author{
doi> http://dx.doi.org/10.33726/akedia2447-7656v5a42018p86-94 \\ Ana Luisa Paziani ${ }^{13}$ \\ Marcelo Pessoa ${ }^{14}$ - iD https://orcid.org/0000-0002-9193-4604
}

RESUMO: Este artigo é fruto de pesquisa de iniciação científica, realizada com o fomento da FAPEMIG - Fundação de Amparo à Pesquisa do Estado de Minas Gerais. Os assuntos aqui dispostos, advém dos estudos realizados pela bolsista, em função da execução de seu Plano de Trabalho, intitulado "KAMAIURÁ - ESTUDO DE CONTEXTOS DE VULNERABILIDADE SOCIOCULTURAL”. A investigação, por sua vez, associa-se ao projeto de pesquisa do orientador, vinculando-a a duas linhas de pesquisa cadastradas pelo grupo SIC - Sociedade, Imagens e Cultura -, no Diretório de Grupos de Pesquisas do CNPq: Estudos Filosóficos Intersemióticos; e, Perfis da Educação Urbana. Metodologicamente, a pesquisa se propõe a investigar nuances da teoria literária e pós-colonial (naquilo em que nelas se veem representadas aspectos da sociedade, da política, da cultura, da produção literária, do atendimento às demandas dos direitos e da educação) que se evidenciem por meio de qualquer meio de veiculação do discurso (na produção artística, nos veículos e meios da comunicação de massa como a música, no jornal, na televisão, na internet, na literatura - de ficção ou não -, nas artes do vídeo, nos fundamentos econômicos, nos postulados da política, da filosofia etc.).

PALAVRAS-CHAVE: Cultura, Sociedade, Direitos, Educação, Kamaiurá.

ABSTRACT: This article is the result of scientific initiation research, held with the encouragement of FAPEMIG - Support Research Foundation of the State of Minas Gerais. The issues herein comes from studies conducted by scholarship, depending on the execution of your work plan, titled "KAMAIURÁ- STUDY of SOCIO-CULTURAL CONTEXTS of VULNERABILITY". The investigation, by your time, associated with the research project of the tutor will linking the two research lines registered by the SIC group-society and Culture-Images, in the research groups of the CNPq: philosophical and semiotics studies; and, Urban Education Profiles. Methodologically, the survey aims to investigate nuances of literary theory and post-colonial (what they see represented aspect of society, politics, culture, literary production, the demands and rights of education) who showing through any means of conveyance of speech (in artistic production, in vehicles and means of mass communication as the music, in the newspaper, on television, on the internet, literature - fiction or not - in the arts, in economic fundamentals, in postulates of politics, philosophy etc.).

KEYWORDS: Culture, Society, Human Rights, Education, Kamaiurá.

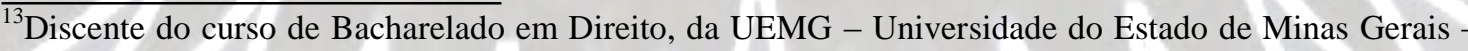
Unidade Frutal. Bolsista de Iniciação Científica da FAPEMIG - Fundação de Ampara à Pesquisa do Estado de Minas Gerais.

${ }^{14}$ Docente da UEMG - Universidade do Estado de Minas Gerais - Unidade Frutal e Professor Orientador dos Grupos de Trabalho.
} 


\section{INTRODUÇÃO}

Para compreendermos o modo como a civilização contemporânea se constrói, notamos que talvez fosse necessário voltarmos no tempo e, de lá, tentar encontrar o fio da meada que nos orientaria na direção do que, hoje, chamamos de destruição de culturas - a aculturação $0^{15}$.

Antes de tecermos juízos de valor sobre o atual modelo civilizatório, dizendo-o mais ou menos evoluído que os formatos primitivos, é preciso que entendamos que a contemporaneidade adota como repertório discursivo o conveniente hasteamento de bandeiras extremamente louváveis, tais como a da "defesa do meio ambiente", a do "respeito às diferenças", e, como no nosso caso, a da "preservação de culturas ancestrais" e assim por diante.

Contudo, percebemos em nossos estudos que, ao longo da história desta mesma civilização, a mesma que ora erige e espalha pilares de sustentabilidade e de tolerância aos quatro ventos, que seu trânsito sociocultural latino-americano dentre categorias de pensamento como a do folclore, ou da língua (tomadas aqui como delimitação dos conteúdos da informação nos estudos etnolinguísticos), do espaço, do território (tomadas aqui como parte das estratégias de construção de vínculos e noções de pertença nos estudos geográficos e antropológicos), da aculturação, da sociedade, da pós-colonização (importantes na definição das identidades e da propriedade nos estudos das ciências sociais), da arte (do modo como a estudamos nos textos sobre ética e estética, no que tange aos processos de desentorpecimento dos mecanismos de percepção do mundo - ARNHEIN, 2004) etc., não tem sido exatamente muito fácil - para não dizermos "antiético" -, especialmente se postos sob a lupa e ótica teórica do modelo teórico póscolonial.

Desse modo, o pós-colonialismo e suas premissas nos parecem ser pertinentes para realizarmos esse tipo de abordagem, uma vez que sob o ponto de vista da pluralidade dos aspectos que esta pauta teórica discute

\footnotetext{
${ }^{15}$ Por aculturação, entendemos, aqui, como tendo o sentido de "processo pelo qual duas ou mais culturas diferentes, entrando em contato contínuo, originam mudanças importantes em uma delas ou em ambas" (LAKATOS E. M. \& MARCONI, M. A, 1999, p. 342).
} 
(folclore, língua, identidade, cultura, território, pertença, ética, estética, educação, direitos etc.), e dos vieses interdisciplinares que naturalmente dessas discussões insurgem, se viabilizam, suportes esclarecedores sobre a natureza dos problemas próprios do processo de colonização da América Latina.

Entender, portanto, a dinâmica desse processo é ponto relevante desta pesquisa, pois, dele, todos nós, sul-americanos, somos herdeiros, o que redunda numa herança de reconstrução, a partir da qual produzimos e reproduzimos todos os nossos discursos, ficcionais ou não, independentemente se fincados nesta ou naquela área do conhecimento.

\section{ENTRELACES HISTÓRICOS E REVESES TEÓRICOS}

Darcy Ribeiro (romancista, etnólogo e político) denuncia em sua vasta obra o aniquilamento da cultura indígena brasileira, sendo que muito dessa destruição é fruto de uma inadequada política interétnica, desenvolvida, tanto pelo Estado quanto por órgãos ao seu serviço, como o Serviço de Proteção ao Índio, atualmente denominado Fundação Nacional do Índio (FUNAI).

Inequivocamente, esta é uma das perspectivas errôneas que determina aposição hegemônica das sociedades ditas mais civilizadas perante as comunidades primitivas. Nesse âmbito, Ferdinand Tonnies, no fim do século XIX, formulou duas conceituações básicas de diferenciação social - enquanto as primeiras organizações sociais (as civilizadas) possuem o comércio e a indústria como atividades econômicas majoritárias, mantendo relações mais impessoais e individualistas por meio de contratos que regem direitos e deveres, as segundas (as sociedades primitivas) são organizações com poderosa coesão social, em que predominam modos de vida mais tradicionais e a transmissão de hábitos, por meio de ritos e da religião, destacando-se o artesanato e a agricultura como atividades preponderantes.

Em expresso antagonismo a essa preconceituosa visão, pois, o referido autor salienta que: 
[...] a comunidade não representa uma organização social primitiva, mas apenas outro tipo de sociabilidade e coesão entre as pessoas. A comunidade também não representa um momento histórico anterior e que precede a sociedade, mas é um tipo de relação social que se perpetua pela ação de fatores diferentes daqueles existentes na sociedade. Nas comunidades, sobressaem-se a tradição e a proximidade; na sociedade, o direito e o Estado (COSTA, 2010, p. 215).

De maneira ainda mais contundente, é possível afirmarmos que o processo de globalização contemporâneo impulsiona uma vertiginosa redução das diferenças existentes entre os numerosos grupos sociais, dentre eles, os indígenas, tornando cada vez mais difícil pensá-los de modo isolado e independente da civilização urbana.

Ao lado disso, entretanto, é inegável salientar que sofrem até hoje as consequências dos processos de aculturação, ou seja, a interferência mútua existente entre uma sociedade e outra. A assimilação, isto é, a transformação cultural que se sucede quando um grupo social minoritário ou subordinado abandona seus traços culturais distintivos e passa a adotar valores e comportamentos do grupo social dominante; e de difusão, fenômeno que transmite um padrão cultural de uma sociedade a outra, havendo a possibilidade de não ameaçar a sociedade receptora:

A indústria, a urbanização e os processos de mobilidade social
acabaram por aproximar as diferentes classes sociais,
tornando-as menos distintas. Os meios de comunicação e a
cultura de massa dissolveram ainda mais as diferenças sociais
e os estilos de vida. No entanto, embora seja menos evidente,
ainda é possível perceber que formas de existência cotidiana,
de expressão e de gosto derivam de posições sociais que
dizem respeito às relações entre classes ou ao acesso que
lhes é determinado pela sociedade aos bens culturais (COSTA,
2010, p. 230).

Ademais, Pierre Bourdieu (2012) demonstra que a oposição entre classes sociais ocorre em distintas posições na estrutura produtiva material, como também na produção simbólica. Conforme seu raciocínio, as diferenças 
culturais são o produto dos variados habitus sociais, responsáveis pela identidade da classe enquanto tal.

Nesse diapasão, é crível elencar mecanismos de poder que legitimam a cultura da classe dominante, visíveis por meio de instituições culturais e educacionais, as quais exercem a força da violência simbólica sobre os "inautênticos subalternos", haja vista que a escola e seus agentes são colaboradores da reprodução social, legitimando e conservando as estruturas sociais:

A ação pedagógica é objetivamente uma violência simbólica, num primeiro sentido, enquanto que as relações de força entre os grupos ou as classes constitutivas de uma formação social estão na base do poder arbitrário que é a condição da instauração de uma relação de comunicação pedagógica, isto é, da imposição e da inculcação de um arbitrário cultural segundo um modo arbitrário de imposição e de inculcação (educação) (BOURDIEU, 2012, p. 27).

Dessa maneira, contextualizadas as problemáticas sociais, torna-se inevitável perguntarmo-nos se o modo particular de emprego ferramentas de regulação social de certos artífices sociais, políticos, literários e culturais é capaz de ajudar a preencher algumas lacunas relativas à compreensão dos processos de opressão e de aculturação dos povos colonizados latinoamericanos e, ainda, se é possível, a partir do estudo de seus modos de expressão artística e de representação social simbólica, balizar um arcabouço crítico próprio do continente e do indivíduo pós-colonizado latino-americano. Noutros termos, o que se pretende obter como resposta, é o modo como os direitos e as garantias sociais, por meio da qual se exprimem (Leis, Tratados, Códigos, Órgãos e Instituições Públicas etc.), pode compor parte do perfil de nossa latinoamericanidad, uma vez que já se sabe que este perfil está disperso em todo tipo de construção simbólica produzida pela política, pela arte e pela cultura de nosso povo (é o que vemos em DaMATTA, 1997, e também em outros estudiosos, quando estes delineiam 0 estereótipo tupiniquim, associando-o a determinadas práticas socioculturais): 
A ação pedagógica é objetivamente uma violência simbólica, num segundo sentido, na medida em que a delimitação objetivamente implicada no fato de impor e de inculcar certas significações, convencionadas, pela seleção e a exclusão que Ihe é correlativa, como dignas de ser reproduzidas, por uma ação pedagógica, reproduz a seleção arbitraria que um grupo ou uma classe opera objetivamente em e por seu arbitrário cultural (BOURDIEU, 2012, p. 29).

Vale dizer ainda, que nossa pesquisa se detém, pelo viés da cultura, no âmbito do approach das questões socioculturais, coloniais e pós-coloniais, cujas aparências ou sequelas históricas são ressentidas por todos os países do mundo que passaram por processos semelhantes de colonização.

De antemão, sabemos que, infelizmente, parte disso tudo foi muito ruim, apesar de existirem fatos bons associáveis às etapas de colonização e de póscolonização em casos isolados. Mas, invariavelmente vimos que as trocas simbólicas socioculturais não são exatamente indolores. Se o colonizador retira algo da colônia, a colônia também fica com algo do colonizador (BOSI, 1992).

Esses indícios de ausências e permanências excessivas, cada nação, ao seu modo, carrega sobre as costas de suas respectivas histórias, e são visíveis por meio de sua produção cultural, de sua manifestação linguística, de sua conjuntura político-econômica, e também, por meio de uma série de sentimentos, lembranças, desencontros, atrasos, fraturas, omissões e culpas recíprocas que podem ser representados sob diversos vieses e modalidades sociais e culturais de interação das quais se valham suas sociedades nos dias de hoje (GOLDMANN, 1987).

A colonização africana, a asiática, a sul-americana deixou nas populações de todas as nações envolvidas, especialmente nas passivas destes processos, resquícios socioculturais negativos, estruturas políticas, econômicas e instâncias psíquicas mal resolvidas.

Neste sentido, esta proposta de pesquisa, ainda em desenvolvimento, acena com um flerte para este ponto, em que os contornos mais sutis de desconforto ante a onipresença constante de um "outro" ideológico em seus territórios geográficos e psíquicos se deixam notar por intermédio deste ou 
daquele viés da cotidianidade linguística - literária, jornalística, ficcional ou literal.

Ou ainda, noutros termos:

\begin{abstract}
A seleção de significações que define objetivamente a cultura de um grupo ou de uma classe como sistema simbólico é arbitraria na medida em que a estrutura e as funções dessa cultura não podem ser deduzidas de nenhum princípio universal, físico, biológico ou espiritual, não estando unidas por nenhuma espécie de relação interna à "natureza das coisas" ou a uma "natureza humana" (BOURDIEU, 2012, p. 29).
\end{abstract}

Por isso, então, despertamo-nos para o interesse quanto ao estudo da solidez ou da fragilidade de sua infraestrutura, da modernização ou atraso de seu parque industrial, de sua clausura ou das relações internacionais, da insuficiência ou robustez de sua economia, da maior ou menor qualidade intelectual de seu povo, da rarefação ou consistência de seu ordenamento jurídico, da oscilação ou estabilidade de sua conjuntura política e do modo como respeitam ou não os direitos civis e os entes humanos (BHABHA, 1998).

\title{
CONCLUSÕES PARCIAIS
}

Diante desse entendimento, já nos é possível compreender parte do desconforto sociocultural das sociedades ditas "primitivas". Nos é compreensível captar a razão pela qual os indígenas brasileiros, portanto, estão cada vez mais perdendo sua "essência", porquanto "o processo cultural, no seu aspecto sincrônico, tende a estabilizar ou cristalizar o padrão (valores, ideias, hábitos, costumes) de determinada cultura" (ASSIS; KÜMPE, 2011, p. 250).

Ressalvando-se que este paradigma normativo é garantido e reforçado por instituições sociais, como as escolas, as quais detém do escopo precípuo de estabilizar a cultura por intermédio do controle social, é correto afirmarmos que as estruturas sociais e os órgãos públicos estão seriamente 
comprometidos com um modelo corroído de atendimento aos direitos e de acessibilidade à educação.

É preciso, pois, reconhecermos também que a escola que reproduz o discurso da civilização citadina não se reduz a um espaço tipicamente urbano, visto que constituído também por salas de aula isoladas no meio rural brasileiro, tendo em vista a sua dispersão em meio à população.

Para, além disso, a educação, os direitos sociais, são, ou menos deveriam ser, sobretudo, um fenômeno concreto que existe e faz parte de um contexto contemporâneo de reiteração dos processos de aculturação, a qual, ainda, deve merecer mais de nossa atenta investigação.

Assim, adentrando mais profundamente nessa temática, a atuação das instituições de ensino é mister no processo de reprodução social e violência simbólica. Consoante aos relatos de uma indígena, chamada Ababy Poran Nhande Yara (Povo Xavante), explícito se torna a ultrapassada visão de que esses povos são primitivos e, logo, subalternos aos brancos, sendo vistos, ainda, como "obstáculo" ao Estado brasileiro, como também ao progresso da nação.

De acordo com sua própria vivência, alegou que órgãos como a FUNAI levam as crianças, na maioria das ocasiões, para escolas de não indígenas, mesmo muitas delas se comunicando em suas respectivas línguas maternas, desconhecendo o português, geralmente não sendo ofertado material escolar algum.

Irrefutável é que não se pode generalizar. Todavia, através da análise de materiais bibliográficos, é plausível depreender que a experiência da índia abordada se repete com inúmeros outros indígenas, em quantidades demasiadamente grandes. Infere-se, portanto, que:

[...] a par de tantos direitos conquistados (inclusive, internacionalmente) já em meio a essa política de interação, no plano fático, ainda existe um grande abismo entre a positivação e a efetivação. Aliás, esse é um ponto negativo em países marcados por desigualdades sociais tão explícitas, especialmente em nações muiti étnicas e pluriculturais como o Brasil. Nesse contexto, embora o percurso seja árduo, e o 
caminho a ser perseguido seja complexo, a efetivação deve ser priorizada e, para esse escopo, a atuação não pode ficar restrita a uma ação estatal, há que se buscar o envolvimento da sociedade como um todo, num processo genuinamente interativo (VILAS BOAS, 2012, p. 160).

Ababy relatou, finalmente, situações em que sofreu preconceito, seja por parte dos demais alunos do colégio, seja pelos próprios professores, os quais, muitos deles não possuíam a mínima instrução de como se portar diante dessas crianças advindas de uma cultura distinta da deles (ainda se sobrepuja o estereótipo do exótico, selvagem); numerosos pais de alunos se manifestaram contra a entrada de indígenas na escola e, até mesmo, chegaram a ameaçar transferir seus filhos para outra instituição, chegou a sofrer, inclusive, discriminação (isolamento, segregação) por parte das demais crianças, como também violência, a título de conhecimento, queimadura (cicatrizes presentes no corpo bem evidentes). E estas, então, são questões a serem exploradas nas próximas fases da pesquisa.

\section{REFERÊNCIAS}

ABABY PORAN NHANDE YARA (Povo Xavante). Palestrante do I/ Simpósio Ambiental da UEMG, realizado nos dias 24 e 25 de maio de 2018.

ARNHEIN, Rudolf. Intuição e Intelecto na Arte. São Paulo: Martins Fontes, 2004.

ASSIS, Olney Queiroz; KÜMPEL, Vitor Frederico. Manual de Antropologia Jurídica: De acordo com o Provimento n. 136/2009. São Paulo: Saraiva, 2011.

BHABHA, Homi K. O Local da Cultura. Belo Horizonte: UFMG, 1998.

BOSI, Alfredo. Dialética da colonização. São Paulo: Companhia das Letras, 1992.

BOURDIEU, Pierre; PASSERON, Jean-Claude.A Reprodução: Elementos para uma teoria do sistema de ensino. 5. ed. Petrópolis, RJ: Vozes, 2012.

COSTA, Cristina. Sociologia: Introdução à ciência da sociedade. 4. ed. São Paulo: Moderna, 2010.

DaMATTA, Roberto. Carnavais, Malandros e Heróis. Rio de Janeiro: Rocco, 1997.

GOLDMANN, Lucien. Dialética e Cultura. Rio de Janeiro: Paz e Terra, 1987.

LAKATOS, Eva Maria \& MARCONI, Marina de Andrade. Sociologia Geral. São Paulo: Atlas, 1999. 